
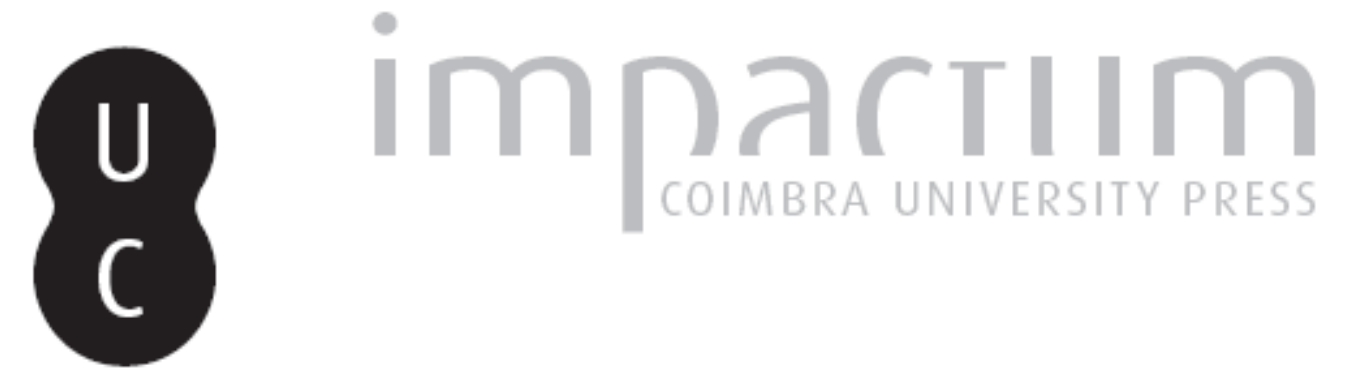

\title{
Colecções científicas e predação cultural
}

Autor(es): $\quad$ Areia, Manuel L. Rodrigues de

Publicado por: CIAS - Centro de Investigação em Antropologia e Saúde

URL persistente:

URI:http://hdl.handle.net/10316.2/41279

DOI:

DOI:http://dx.doi.org/10.14195/2182-7982_18_9

Accessed : $\quad$ 26-Apr-2023 12:13:48

A navegação consulta e descarregamento dos títulos inseridos nas Bibliotecas Digitais UC Digitalis, UC Pombalina e UC Impactum, pressupõem a aceitação plena e sem reservas dos Termos e Condições de Uso destas Bibliotecas Digitais, disponíveis em https://digitalis.uc.pt/pt-pt/termos.

Conforme exposto nos referidos Termos e Condições de Uso, o descarregamento de títulos de acesso restrito requer uma licença válida de autorização devendo o utilizador aceder ao(s) documento(s) a partir de um endereço de IP da instituição detentora da supramencionada licença.

Ao utilizador é apenas permitido o descarregamento para uso pessoal, pelo que o emprego do(s) título(s) descarregado(s) para outro fim, designadamente comercial, carece de autorização do respetivo autor ou editor da obra.

Na medida em que todas as obras da UC Digitalis se encontram protegidas pelo Código do Direito de Autor e Direitos Conexos e demais legislação aplicável, toda a cópia, parcial ou total, deste documento, nos casos em que é legalmente admitida, deverá conter ou fazer-se acompanhar por este aviso.

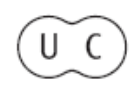


Antropologia Portuguesa

Volume $18 \cdot 2001$

Departamento de Antropologia | Universidade de Coimbra 


\title{
Colecções científicas e predação cultural
}

\author{
Manuel L. Rodrigues de Areia \\ Departamento de Antropologia \\ Universidade de Coimbra \\ 3000-056 Coimbra, Portugal \\ areia@ci.uc.pt
}

Resumo A recolha de colecções para fins científicos foi uma política generalizada com as "viagens filosóficas" do séc. XVIII. O reconhecimento prático da diversidade cultural implica um olhar novo sobre essas colecções que permitirá a sua reaproximação aos povos e locais que as produziram. A semelhança dos movimentos em defesa do biodiversidade também a defesa da diversidade cultural ganha adeptos em torno de patrimónios culturais esquecidos e da discussão do conceito de propriedade cultural.

Palavras-chave Diversidade cultural; predação cultural; propriedade cultural.

Résumé Le recueil de collections à des fins scientifiques s'est inscrit dans une politique générale à partir des "voyages philosophiques" du XVIIIe Siècle. La reconnaissance pratique de la diversité culturelle implique un nouveau regard sur ces collections, ce qui permettra un rapprochement avec les peuples et les lieux qui les ont produit. À l'égal des mouvements de défense de la biodiversité, la défense de la diversité culturelle gagne des adeptes qui s'interrogent sur le statut des patrimoines culturels "oubliés" et sur le concept de propriété culturelle.

Mots-clefs Diversité culturelle; prédation culturelle; propriété culturelle. 


\section{A magia dos crânios}

Numa altura em que alguns antropólogos dão sinais de certa desorientação (situação que decorre de levarem longe demais uma prática de fazer antropologia sem anthropos) parece valer a pena voltar ao princípio e tentar perceber o que entusiasmou os nossos antepassados (antropólogos) mais longínquos, os fundadores da Antropologia Física. Uma primeira nota que chama a nossa atenção é a magia dos crânios! A ideia de que a cabeça, coroamento natural do corpo, é a sede do pensamento está na base da sedutora hipótese de F. J. Gall ao tentar localizar no cérebro as faculdades mentais. Nascia a frenologia e a consequente caça aos crânios, sobretudo os mais diferentes (supostamente), os mais primitivos, os que estariam mais perto do homem-macaco, os mais distantes do homem actual!

Toda a instituição que quisesse estudar o Homem investia prioritariamente na constituição de uma boa colecção de crânios. As primeiras de que há informação escrita terão sido a de S. Morton, "Crania Americana" (1838) e a de J. B. Davis "Thesaurus Craniortum. Catalogue of skulls of the various races of man" (1867). De onde vieram estes crânios? Antes de mais, da vala comum, das igrejas, dos campos de batalha, mas também de regiões longínquas... Peru, Tebas, Gizé... (Luyendijk-Elshout, 1997; Kaufman e Basden, 1997). Começava o tráfico dos crânios e uma das primeiras formas de predação cultural: profanação de túmulos, assaltos a lugares sagrados, comércio ilegal dos sítios arqueológicos.

Simultaneamente avança em termos políticos um processo intenso de colonização, depois da América, a África. As primeiras formas de contacto depressa degeneram em formas de dominação política e militar e as armas gentílicas são o espólio mais abundante das primeiras colecções coloniais a que se juntaram rapidamente os elaborados símbolos do poder (gládios, cadeiras, bastões, machados, etc). Também não é por acaso que boa parte das colecções iniciais que deram origem aos actuais museus de etnografia colonial são as da Marinha, de Administradores Coloniais ou de Missionários. Ainda que em muitos casos haja informação de negociação, e até de preços concretos na aquisição de alguns objectos, fica também claro que a fronteira entre negociação e imposição foi muitas vezes ultrapassada. A questão da pilhagem cultural nesta circunstância é, sobretudo, contextual. 
De resto, a Europa colonizadora detém nas suas tradições uma ampla prática de confiscar bens como tributo de guerra. Merece ser lembrado aqui, e referindo apenas o caso português, o que as tropas napoleónicas levaram de Lisboa em 1808 e que C. Almaça (1987) resume sob a epígrafe "O saque de Saint-Hilaire":

"O saque de Saint-Hilaire, também essencialmente baseado em exemplares do Brasil, compreendeu 76 exemplares de 65 espécies de Mamíferos, 387 exemplares de 239 espécies de Aves, 32 exemplares de 25 espécies de Répteis e Anfibios, 100 exemplares de 89 espécies de Peixes, 508 exemplares de 209 espécies de Insectos, 12 exemplares de 5 espécies de Crustáceos, 468 exemplares de 272 espécies de Moluscos e Cirrípedes (conchas), 42 amostras de fósseis, 10 herbários incluindo 2855 plantas ( 3 de plantas do Brasil, o maior dos quais, com 1114 exemplares, feito por $A$. R. Ferreira, I da Costa de Angola, 1 do Cabo da Boa Esperança, 1 do Perú, 1 de Cabo Verde, I de Goa, 1 da Conchinchina e I da Suécia), 25 amostras de produtos vegetais do Brasil (raizes, frutos e ritidomas), 161 amostras de minerais e rochas do Brasil, 12 amostras de minerais e rochas de Portugal, 5 amostras de minerais e rochas de Cabo Verde, Angola e México e, ainda, 5 manuscritos originais, num total de 19 volumes, sobre a flora e fauna brasileiras. Apenas os manuscritos foram devolvidos, em 1814" (Almaça, 1987:297-299).

No recibo relativo à aquisição deste espólio, com data de 8 de Junho de 1808 o naturalista G. Saint-Hilaire lembra em que condições estas colecções foram levantadas:

"Le Duc d'Abrantes, Général en Chef de l'Armée du Portugal, autorise Mr. Geoffroy, Membre de l'Institut de France envoyé par le Ministre de l'Intérieur pour faire des recherches sur les objets de Histoire Naturelle existants en Portugal et utiles au Cabinet de Paris, à enlever et faire encaisser pour être transportés en France les objets spécifiés dans le present..." (in Almaça, 1996:19).

Poderíamos ainda descer a um nível mais restrito e verificar como a predação cultural se ajusta perfeitamente, a nivel nacional, a uma politica de salvaguarda e protecção do património nacional. Permito-me exempli- 
ficar para ser concreto. Pude, há anos, ver uma bela exposição de pintura na cidade de Évora. Grande parte das telas expostas pertencia ao Museu de Arte Antiga, de Lisboa, mas tinha sido levada de igrejas de Évora. Afinal o Museu de Arte Antiga mostrava aos eborenses simplesmente o que lhes pertencia ou recriava um novo laço com os antigos "donos"? Ou desafiava-os para lembrar: isto foi vosso mas já não o é. A ambiguidade da situação permite todas as leituras.

O centralismo estatal pode justificar tudo e as razões circunstanciais invocadas no momento da acção, mesmo que caducadas pela evolução das circunstâncias, permanecem nos seus efeitos como se fossem actualmente válidas. Uma invocada tipologia da arte em Portugal incluindo peças de diferentes pontos do pais, nomeadamente de velhos conventos e igrejas, situados em lugares inacessiveis, de segurança precária, condições complicadas de conservação, etc, etc terão sido justificação suficiente para a pilhagem oficial das peças de arte antiga. Alguém verá um dia, essas peças voltarem ao lugar da sua origem? Será razoável que voltem?

Um número significativo de museus, sobretudo os museus etnográficos, quando fruto de pilhagem, perderam as musas. Eles tornaram-se simplesmente um encarceramento dos deuses!

Se a geração actual tanto clama por liberdade será que deixará os deuses encarcerados indefinidamente? Não é fácil responder a esta pergunta; é de prever que se consiga contrariar a circulação forçada, clandestina e ilegal dos bens culturais a favor de uma circulação livre, aberta e espontânea dos deuses, das musas e dos seus intérpretes. Mas o poder sempre quererá enfeitar-se com obras de arte... A negociação cooperativa (a nivel internacional ou global) será bem mais enriquecedora em termos de partilha comum (com regras) dos bens culturais do que a actual situação decorrente da lógica de escondimento, esquecimento e encarceramento.

\section{Alguns casos paradigmáticos}

\section{Memória da Amazónia (1997)}

A exposição Memória da Amazónia-expressões de identidade e afirmação étnicas apresentada no Palácio do Rio Negro na cidade de Manaus, entre 3 de Abril e 3 de Junho de 1997, constitui uma experiência muito rica para uma abordagem prática da questão aqui suscitada. 
Numa iniciativa conjunta das Universidades do Amazonas, do Porto e de Coimbra, foi possível levar a Manaus um conjunto de 300 objectos colectados durante a "Viagem Philosophica" do naturalista Alexandre Rodrigues Ferreira pela Amazónia no decurso de 9 anos (1783-1792).

Pela primeira vez um conjunto tão rico e tão diverso de peças amazónicas voltava à região de origem após um periodo de mais de duzentos anos. A Universidade do Amazonas empenhara-se profundamente, com o apoio das autoridades federais, em fazer chegar do interior amazónico um número expressivo de representantes das nações indígenas para os pôr em contacto com esse património cultural. As reacções foram duplamente surpreendentes: para os representantes das nações indigenas, mas também para as autoridades culturais brasileiras. De facto tratava-se de um conjunto de objectos longamente esquecidos, parte em Coimbra (Museu Antropológico da Universidade de Coimbra), parte em Lisboa (Academia das Ciências de Lisboa) e dos quais se fez uma primeira selecção em 1990 para uma exposição integrando as Comemorações dos 700 Anos da Criação da Universidade de Coimbra (1290-1990) (Areia et al., 1991).

Ainda em 1990, e quando estavam apenas escolhidos os artefactos para o exposição comemorativa da Universidade, um responsável da Secretaria de Estado da Cultura do Brasil, passando por Coimbra, manifestou interesse em ver o espólio seleccionado. Olhando com espanto para as extraordinárias máscaras em entrecasca, para as esplêndidas jarras de argila, para os sofisticados instrumentos musicais e para as pranchetas de aspirar paricá, o visitante interpelou-me com alguma incredulidade:

"O Senhor está-me dizendo que estes objectos foram feitos pelo índio da Amazónia?" Sem dúvida alguma - respondi.

Ao que me retorquiu: "Não o poderia acreditar".

Esta foi a primeira grande surpresa: os objectos a expor, artefactos de ameríndios de há 200 anos revelavam uma qualidade incomparavelmente superior aos que hoje são divulgados nos centros de comercialização da Fundação Nacional do Índio (FUNAI). De certo modo se reencontravam importantes exemplares do que foram os bens de prestígio das antigas sociedades amazónicas.

Mas um dos propósitos era fazer chegar estes tesouros ao contacto e conhecimento de responsáveis das naçōes indigenas actuais. E aí as surpresas foram ainda mais notáveis. 
Em Manaus, quando um grupo de indígenas afectos à etnia Yanomamo (Noroeste do Brasil e Sudeste da Venezuela) entrou na sala onde se encontravam as máscaras, sentiram-se perturbados e sofreram como que um arrepio (informação da gestora da exposição).

As máscaras de entrecasca expostas foram atribuídas pelo colector Alexandre Rodrigues Ferreira aos indios Jurupixuna que aparentemente estão extintos, embora haja nações indígenas com afinidades, nomeadamente os Yanomamo.

A verdade é que a natureza sagrada e secreta conferida a máscaras que os actuais indios não conheciam, mas de que ouviram falar, os perturbou porque elas carregavam poderes sobrenaturais dos antepassados. De imediato aqueles índios pediram à responsável para fechar ao público a exposição enquanto realizavam um ritual aos ditos antepassados (uma espécie de acto de desagravo). Assim foi feito e tentando perceber o que os perturbara e o que se alterou com o referido ritual, as expressões explicativas eram vagas: "o ambiente estava muito carregado...", "não dava para aguentar...", "agora já se pode respirar...". No entanto, a tentativa para vetar a entrada de mulheres passou por uma negociação mais elaborada: eles, os índios, podiam impedir a entrada de mulheres indigenas à sala das máscaras, mas não a de mulheres brancas.

O terceiro aspecto, e talvez o mais importante para a questão em debate, foi a discussão em torno de uma hipotética reapropriação dos objectos e até da hipótese provocatória do seu não retorno a Portugal. Limito-me a anotar o que observei em alguns dias de permanência e a transmitir aspectos de discussões directas, em que estive envolvido. Fazendo-se eco de algumas posições reinvindicativas transmitidas e, em muitos casos, provocadas pela imprensa, a TV Cultura de Manaus organizou um debate com alguns jornalistas formulando perguntas à antropóloga brasileira Lux Vidal e a mim próprio.

A Professora foi a primeira a ser confrontada com a questão do regresso, ou não, das peças a Portugal. Lux Vidal foi directa ao assunto: os artefactos haviam sido recolhidos num contexto de pesquisas cientificas que à época eram vistas não só como legítimas (o Brasil fazia parte de Portugal), mas até como indispensáveis para o progresso científico.

Havia a acrescentar um facto relevante: as colecções foram preservadas (tê-lo-iam sido se ficassem no Brasil?) e os povos indígenas puderam rever-se nelas, o que constituía um dado muito positivo. Mas as peças 
deviam regressar a Portugal até porque outros objectos etnográficos da Amazónia pertencentes a diferentes museus brasileiros não abonavam nada de favorável quanto às condições de preservação...

Confrontado com esta questão não pude deixar de sublinhar alguns aspectos do problema que me pareciam (e ainda parecem) essenciais:

- A importância da aproximação fisica, ainda que ocasional, entre tesouros do passado e actuais descendentes dos que os produziram convocava, obviamente, a auto-estima destes povos. Mas também é obvio que dai não decorre necessariamente uma pura devolução que, de resto, não seria apenas muito complexa, mas mesmo impossível de concretizar, por dificuldade de identificação objectiva dos pretensos destinatários.

- A auto-estima também se desenvolve quando uma nação indigena vê reproduzidas imagens de objectos fabricados pelos seus antepassados, em catálogos que correm o mundo ou quando esses objectos são expostos em Lisboa e Nova York, como me referia um alto dignitário indigena ao visitar a Universidade de Coimbra em 1994. Na sua perspectiva a maior segurança (condições de preservação) e a suficiente divulgação valiam mais que um problemático retorno. Mas esta não é, certamente, a posição da maioria dos responsáveis das nações indigenas do Brasil.

- A questão, no momento puramente académica, poderia pôr-se e ponderar as suas consequências. Numa primeira análise, não havendo nas nações indigenas prática de guardar esses objectos em colecções (as máscaras iniciáticas, por exemplo, eram destruídas no fim do ritual) não existiria diferença substancial em serem geridos por um museu brasileiro ou um museu europeu. Admitindo que estas nações evoluam, também elas, para a prática de preservarem colecções (na época estava em formação um museu dos Tikuna...) então poder-se-ia levantar a questão de uma eventual política de restituição a começar pelas peças dos "museus dos índios" existentes no Brasil e depois isso poderia até completar-se com objectos vindos da Europa, Portugal, Alemanha, Rússia, etc.... A matéria era problemática mas não havia que fugir a ela: no imediato os objectos voltavam aos museus de onde vieram nos termos protocolares acordados entre Portugal e Brasil. Assim aconteceu.

- É obvio que a complexidade da questão (esta como outras) corre o perigo de desembocar num diálogo de surdos. Dois pressupostos frequentemente invocados levariam a essa situação de impasse: 
Por um lado, os que reduzem todas as formas de colonização a colonialismo puro e vêem em todas as formas de contacto entre os povos uma sequência de maldições históricas. Nessa perspectiva a posição é muito simples: "isso não vos diz respeito, devolvam o que nos tiraram...".

Outra posição, igualmente radical, é a que defende que estes objectos fazem parte integrante da história do país colonizador; que ao organizar colecções de produtos exóticos fundara uma praxis nova - a colecção museológica - e que com essa invenção criara condiçōes de prolongar a vida a objectos efémeros por natureza e uso. Nesta perspectiva interessa menos o que esses objectos foram (na sua origem) e importa mais o que eles são e representam para os actuais detentores.

A questão promete grandes discussões, como se vê, mas à partida só parece haver uma alternativa ao inútil e desgastante diálogo de surdos; essa alternativa passará sem dúvida, e antes de mais, por formas inovadoras de cooperação cultural.

E porque nesta questão cada caso tem o seu aspecto particular permito-me referir de passagem outros que merecem, igualmente, reflexão.

\section{A túnica da dança dos espíritos dos Índios Sioux (E.U.A.)}

Sob o título "Escoceses devolvem símbolo nacional dos Sioux" o correspondente do jornal Público, em Londres (20/11/1998) dava conta da devolução de uma velha túnica exposta no museu Kelvingrove, em Glasgow, a organizações de índios norte-americanos que a reclamavam desde 1993. O jornal relata esta história em breves palavras. Destaco apenas o que me parece mais significativo. Antes de mais o facto de a peça ser mais do que centenária no museu, o que lhe confere, desde logo, um valor museal particular. De facto, a velha túnica tinha entrado no Kelvingrove em 1892, integrando o espólio de artefactos índios vendidos por G. Crager ao museu. Quando, em 1993, um visitante norte-americano, John Earl, a descobriu entendeu que os índios a deviam reclamar aos representantes dos ancestrais proprietários até porque, dizia Earl, "ela tem um valor que é dificil de explicar a quem não é indio. Ela não está a fazer nada em Glasgow". O discurso do "valor cultural" e "emocional" estava lançado. $O$ interessante neste caso é a consulta feita pela cidade aos munícipes e, se das 104 cartas de resposta à questão apenas 8 se opunham à devolução, percebe-se que, de facto, a túnica não desempenharia um papel de destaque no museu. A questão de saber o que é que ela iria fazer 
nas organizações dos índios e ao cuidado de quem, constituia uma decisão a tomar pelos mesmos, embora a Câmara de Glasgow quisesse o assunto esclarecido antes da entrega. Também é interessante saber que o conservador do museu, Mark O'Neil, defendeu a manutenção da peça no museu pelo seu "valor didáctico" e por ser única, fora dos Estados Unidos (Anunciação, 1998).

Este "sim" de Glasgow tem que ser ponderado com o "não" do Museu Britânico a Kabwe (Broken-Hill) (ver Os muitos casos africanos) e com um "talvez", amanhã, de uns tantos museus a pedidos semelhantes. A questão desta velha túnica vale assim como um sinal dos tempos em que à confrontação cultural (com prejuízo para todos) deve suceder, e por mecanismos adequados, um processo de cooperação cultural de interesse mútuo. Quando vejo as nossas grandes colecções etnográficas, quase sempre esquecidas (e diria, paradoxalmente, nalguns casos preservadas porque esquecidas) pergunto-me qual seria o resultado de uma decisão "democrática" com base em consulta popular aos munícipes das cidades onde jazem essas colecções?

O caso de Glasgow ( 8 contra a devolução em 104 respostas) talvez indicie um misto de inconsciente colectivo e de má consciência face à piIhagem fundadora.

\section{Os muitos casos africanos}

Em questões de circulação ilícita de património cultural, a África continua a ser o continente de maior destaque.

Impressionados com a intensidade crescente deste fenómeno em toda a África os responsáveis do ICOM (International Council of Museums) organizaram um debate para discutir a questão no contexto do Africom Programme da mesma instituição. Os diferentes testemunhos (Documents de Travail) publicados e enviados aos participantes do "Atelier sur la protection du patrimoine culturel africain" (Amsterdão, 2224/09/1997) mostram que a pressão compradora é actualmente tão forte que todas as formas de regulamentar a saída ilegal de património se têm verificado insuficientes e até inúteis (ICOM, 1997a). E não se trata apenas de pilhagem de sítios arqueológicos ou património disperso nas populações. Nem os museus são poupados.

Muitos objectos guardados em museus nacionais saem clandestinamente de África e desaparecem nas mãos de muitos coleccionadores pri- 
vados da Europa e da América do Norte quando não acabam até por entrar em museus oficiais destas regiões. Neste aspecto a descolonização cultural ainda não ocorreu. Alertando para esta realidade o ICOM (1997b) publicou com as devidas ilustrações e informações, uma listagem de cem peças desaparecidas de África, Pillage en Afrique:cents objets disparus Looting in Africa: one hundred missing objects. É apenas a ponta do icebergue. Para alguns casos que me parecem significativos da complexidade deste problema em África, remeto o leitor para algumas observações de um texto anterior (Areia, no prelo).

\section{As colecções científicas e o conceito de propriedade cultural}

A crise existencial que perpassa os museus etnográficos estimulou, nas últimas décadas, uma reflexão sobre a própria natureza do património desses museus. Questionou-se a hipótese, não só de uma nova relação com os povos de onde provieram os objectos etnográficos (KleiberSchwartz, em 1992, levanta a questão de como transformar um museu colonial em museu de comunidades), mas também as possibilidades do estudo do meio ambiente em que eles foram produzidos. As muito diversas abordagens da arte dita "arte etnográfica" (primitiva, primeira, étnica, tribal, longínqua!) introduziram alterações fundamentais na definição (agora menos etnocêntrica) do objecto de arte e do conceito de produção artistica.

As questões de identidade cultural (hoje muito na moda) alargaram - campo de discussão ao complexo conceito de propriedade cultural (Berman, 1997), o que multiplica o grau de complexidade quando aplicado a objectos rituais de origem e significado comunitários. Nestes casos surgem muitas questões de natureza quase filosófica. Quem é, por exemplo, o proprietárjo de uma máscara iniciática? E a quem pertence a cultura que a produziu? $\mathrm{E}$ os valores que ela transporta? E a estética que nela admiramos? E, inevitavelmente, a quem pertence o museu que a guarda? Sabendo que mesmo na sociedade ocidental a propriedade cultural se aplica aos direitos de produção, uso e propriedade, como se poderá ignorar quem a produziu e quem a usou?

Sendo grande parte das colecções científicas propriedade de sociedades que não as produziram, parece fazer sentido a distinção proposta 
por Davallon (2002) entre objectos-memória, em continuidade com as sociedades que os produziram (colecções endógenas) e objectos-documento, objectos que testemunham culturas diferentes das sociedades que os guardam (colecções exógenas).

Se as colecções de etnografia portuguesa representam, indiscutivelmente, o nosso passado, ou antes, o que ficou do nosso passado, e como tal são património nosso, já parece discutivel a ideia de patrimonializar os objectos-documento, exógenos, trazidos do exterior. É verdade que o objectivo do comparativismo científico teve sempre como ideal a criação de um museu que fosse, quanto possivel, o Museu do Homem (o Museu Nacional de Etnologia, com as ricas colecções de etnografia portuguesa e as diversificadas colecções coloniais, mantém esse ideal que vem do Professor Jorge Dias, seu fundador). A Antropologia e Arqueologia foram certamente as ciências que mais contribuíram, até agora, para a patrimonialização das colecções exógenas com base no ideal da "humanidade comum". Para o caminho ser viável ele não poderia ter sentido único. Algo de parecido com a mestiçagem biológica deveria acontecer, chamese, ou não, mestiçagem cultural.

Um primeiro passo para a reformulação destas questões seria admitir que as colecções científicas deveriam contribuir, antes de mais, para o conhecimento dos povos que as produziram, nomeadamente quando esses povos integram grupos que lutam pela sua afirmação ou simplesmente pela sobrevivência da sua cultura como é o caso de muitas nações indigenas no Brasil e muitos grupos étnicos integrados em modemos estados africanos.

No entender de Handler (1997) "esta questão veio trazer para o centro da discussão antropológica uma realidade (as colecçōes, os museus) que foi marginal durante muito tempo. Os museus tornaram-se peças fundamentais no processo de identidade cultural dos povos - mais do que lugares de depósitos culturais, também eles, se tornaram (e tornam cada vez mais), lugares de produção de teoria cultural". Esta situação confere um sentido novo e responsabilidades acrescidas às instituições museológicas.

\section{Bibliografia}

Almaça, C. 1987. A Zoologia e a Antropologia na Escola Politécnica e na Faculdade de Ciências da Universidade de Lisboa (até 1983). In: Gil, F. B.; 
Canelhas, M. G. S. (coord.) Faculdade de Ciencias da Universidade de Lisboa: passado / presente perspectivas futuras. Catálogo. Lisboa, Museu de Ciência da Universidade de Lisboa: 293-312.

Almaça, C. 1996. A Natural History Museum of 18th century: the Royal Museum and Botanical Garden of Ajuda. Lisboa, Museu Nacional de História Natural. Anunciação, P. 1998. Escoceses devolvem símbolo nacional dos Sioux. Público, 20 de Novembro de 1998.

Areia, M. L. Rodrigues de; Miranda, M. A.; Hartmann, T. 1991. Memória da Amazónia. Coimbra, Museu e Laboratório Antropológico da Universidade de Coimbra.

Areia, M. L. Rodrigues de [no prelo]. Para nova relação com África uma nova responsabilização sobre o património cultural africano. In: III Congresso de Estudos Africanos no Mundo Ibérico. Novas Relações com África: que Perspectivas? Lisboa, 2001.

Berman, T. 1997. Beyond the museum: the politics of representation in asserting rights to cultural property. Museum Anthropolog', 21 (3): 19-27.

Davallon, J. 2002. Les objets ethnologiques peuvent - ils devenir des objets de patrimoine? In: GHK (eds). Le Musée camibale. Neuchâtel, Musée d'Ethnographie: $169-187$.

Handler, R. 1997. Cultural property, cultural theory and museum Anthropology. Museum Anthropology, 21 (3): 3-4.

ICOM, 1997a. Africom programme: atelier sur la protection du patrimoine culturel africain. Document de travail. Paris.

ICOM, 1997b. Pillage en Afrique: cent objets disparus. Looting in Afica: one hundred missing objects. Paris

Kaufman, M. H.; Basden, N. 1997. Marked phrenological heads: the evolution with particular reference to the influence of George Combe and the Phrenological Society Edinburgh. Joumal of the History of Collections, 9 (1): 139-159.

Kleiber-Schwartz, L. 1992. Du Musée des colonies au musée des communautés. Musetm, ñ ${ }^{\circ}$ 175, 44 (3): 137-141.

Luyendijk-Elshout, A. M. 1997. Opening address: the magic of the skull. 'Commercium Craniorum' in the nineteenth century. International Joumal of Osteoarchaeologi; 7 (6): 571-574. 